Check for updates

Cite this: RSC Adv., 2018, 8, 13186

Received 12th January 2018 Accepted 22nd March 2018

DOI: $10.1039 / \mathrm{c} 8 \mathrm{ra00346g}$

rsc.li/rsc-advances

\section{A tin(Iv) oxides/carbon nanotubes composite with core-tubule structure as an anode material for high electrochemistry performance LIBs}

\begin{abstract}
Yu Ji, (D)* Li Li, Yang Zhenyu (D) and Cai Jianxin
$\mathrm{SnO}_{2} / \mathrm{CNTS}$ composites with core-tubule structure are prepared by a facile wet chemical method. The investigation of electrochemical characteristics of the $\mathrm{SnO}_{2} / \mathrm{CNTS}$ composites shows that the composites exhibit some advantages, such as stable core-tubule structure, small particle size of $\mathrm{SnO}_{2}$, low electron-transfer resistance and faster lithium ion migration speed. The final product synthesized under optimized conditions can release a stable capacity of about $743 \mathrm{~mA} \mathrm{~h} \mathrm{~g}^{-1}$ after 100 cycles at the current density of $0.4 \mathrm{~A} \mathrm{~g}^{-1}, 598 \mathrm{~mA} \mathrm{~h} \mathrm{~g}^{-1}$ after 500 cycles at the current density of $4 \mathrm{~A} \mathrm{~g}^{-1}$. Even at a super high current density of $8 \mathrm{~A} \mathrm{~g}^{-1}$, the composite can still deliver a steady capacity of $457 \mathrm{~mA} \mathrm{~h} \mathrm{~g}^{-1}$, and the discharge capacity can be restored to $998 \mathrm{~mA} \mathrm{~h} \mathrm{~g}^{-1}$ when current density is decreased to $0.4 \mathrm{~A} \mathrm{~g}^{-1}$.
\end{abstract}

\section{Introduction}

Carbon nanotubes (CNTs) have much promise for application in LIBs owing to the high conductivity, high specific surface area, good permeability properties of lithium and stable electrochemistry. ${ }^{1-3}$ These properties made CNTs an optimum support matrix for composites. ${ }^{4,5}$ However, CNTs displayed a low charge \& discharge capacity as an anode material for LIBs which limited its application in lithium-stored materials. ${ }^{6}$ Many scholars believed that a crafted combination of CNTs and highcapacity lithium-stored compounds like $\mathrm{Sn}, \mathrm{Cu}, \mathrm{Si}, \mathrm{Fe}, \mathrm{Ni}$ or their oxides and so on may work to display both high capacity and good cyclability. ${ }^{7-11}$

$\mathrm{SnO}_{2}$-based materials are perceived as attractive anode materials for LIBs due to their high theoretical capacity, environmental benignity, and widespread availability. ${ }^{12}$ However, the high discharge capacity is usually accompanied with large volumetric change during charging and discharging, which results in rapid capacity decay of the active materials. ${ }^{13}$ Two major methods have been developed to enhance the structural stability and electrochemical performance of $\mathrm{SnO}_{2}$-based anodes. The first is based on structuring the $\mathrm{SnO}_{2}$-based materials themselves, such as $\mathrm{SnO}_{2}$ nanoparticles, ${ }^{14}$ nanowires ${ }^{15}$ nanotubes,${ }^{16}$ hollow nanospheres, ${ }^{17}$ nanocubes ${ }^{18}$ and nanosheets. ${ }^{19}$ The other complementary method is to employ flexible carbon coatings, which act as a soft matrix, to accommodate the mechanical stress caused by volume expansion. ${ }^{20,21}$ A series of $\mathrm{SnO}_{2} / \mathrm{CNTs}$ composites have been designed and developed in recent years, such as tin oxides adsorbed on the

College of Chemistry, Nanchang University, No. 999 Xuefu Road, New District of Honggutan, Nanchang 330031, PR China. E-mail: yuji@ncu.edu.cn; Tel: +86-791-83969514 surface of $\mathrm{CNTs}^{22}$ and $\mathrm{SnO}_{2} @$ carbon hollow spheres. ${ }^{23,24}$ It suggests that CNTs can not only relieve the volume change, inhibiting aggregation, but also enhance the conductivity of the composites. ${ }^{25,26}$ Moreover, many efforts have been devoted to fill foreign materials into the hollow cavity of CNTs. ${ }^{27,28}$ Usually electrochemical deposition, solution-chemistry method and capillary forces action (physical deposition) are regarded as the commonly used techniques. ${ }^{29,30}$

Herein, we reported a special structure of $\mathrm{SnO}_{2} / \mathrm{CNTs}$ coretubule composite and studied the effect of reaction times on the electrochemical performance of the composite as anode materials for LIBs.

\section{Experimental}

CNTs were provided by Nanjing Ji Bin Nanometer Science and Technology Co., Ltd. (Nanjing, China) and used as received. The inner and outer diameters of the CNTs were $20-50 \mathrm{~nm}$ and $30-$ $60 \mathrm{~nm}$ measured by TEM (JEM-200CX, operated at $200 \mathrm{kV}$ ). CNTs were treated before used as the container of $\mathrm{SnO}_{2}$. A typical procedure was described as follows: the CNTs were dispersed in distilled water by ultrasonic wave for half an hour and then soaked in $30 \%$ hydrogen peroxide for $5 \mathrm{~h} .{ }^{31} \mathrm{After}$ that the CNTs were refluxed in nitric acid solution $(20 \mathrm{wt} \%)$ at $100{ }^{\circ} \mathrm{C}$ for another $5 \mathrm{~h}$. In the end, the treated-CNTs were rinsed and dried at $80^{\circ} \mathrm{C}$ and then the open-tips CNTs were obtained (see the Fig. 2(a) and (b)).

About $100 \mathrm{mg}$ treated-CNTs were putted into a round bottom flask. Then the flask was evacuated and a aqueous solution of $\mathrm{SnCl}_{2}$ and $0.5 \mathrm{ml} \mathrm{HCl}(37 \%)$ was added into the flask by an injector. The mixture was stirred at room temperature and the flask was maintained vacuum state for $8 \mathrm{~h}, 16 \mathrm{~h}, 24 \mathrm{~h}, 48 \mathrm{~h}, 64 \mathrm{~h}$, $72 \mathrm{~h}$ and $100 \mathrm{~h}$ to complete the filling process. After that the 


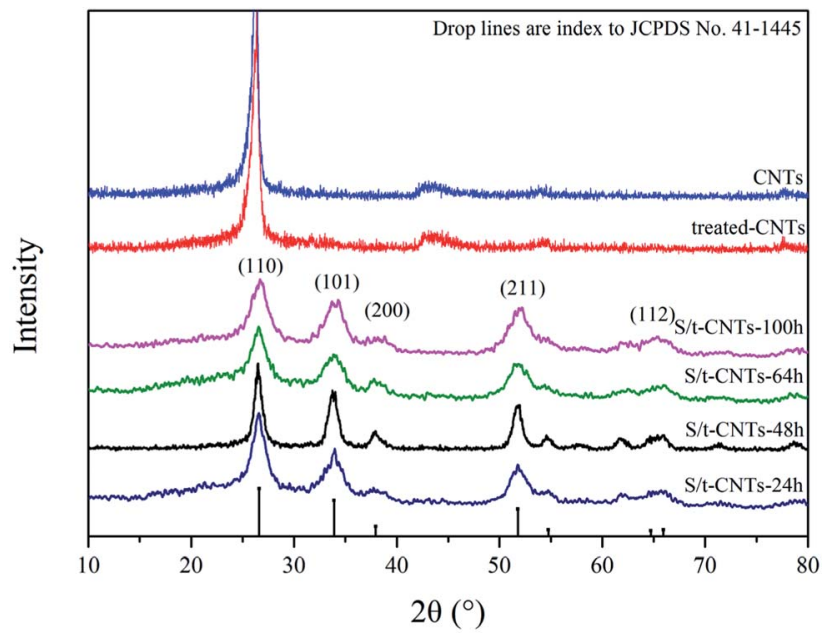

Fig. 1 XRD patterns of S/t-CNTs-24 h, $-48 \mathrm{~h},-64 \mathrm{~h},-100 \mathrm{~h}$, treatedCNTs and CNTs.

solution were refluxed at $140{ }^{\circ} \mathrm{C}$ for $3 \mathrm{~h}$, and the black samples were collected and washed by ethanol for several times to remove the attachments of outside of CNTs as far as possible. The samples were dried at $60{ }^{\circ} \mathrm{C}$ for $12 \mathrm{~h}$, and then calcined at $400{ }^{\circ} \mathrm{C}$ for $2 \mathrm{~h}$ under the protection of argon. The final samples were marked as S/t-CNTs- $8 \mathrm{~h}, \mathrm{~S} / \mathrm{t}-\mathrm{CNTs}-16 \mathrm{~h}$ and so on according the reaction time.

The as-samples were characterized by X-ray powder diffraction (XRD) using a Rigaku D/Max-IIIA X-ray diffractometer with $\mathrm{Cu} \mathrm{K} \alpha$ radiation $(\lambda=1.54178 \AA)$. Morphology and structure of the as-samples were examined by scanning electron microscopy
(SEM, FEI Quanta 200F) and transmission electron microscopy (TEM, JEM-200CX). Thermogravimetric analysis (TGA) was carried out on a thermogravimetric-differential scanning calorimetry (TG-DSC) analyzer (Mettler-Toledo, TGA/DSCI-LF-1100) in air from room temperature to $1000{ }^{\circ} \mathrm{C}$ with a heating rate of $5{ }^{\circ} \mathrm{C} \mathrm{min}^{-1}$.

Electrochemical measurements were carried out using cointype half cells (CR2025 type) with lithium metal as the counter electrode. The working electrodes consisted of $84 \mathrm{wt} \%$ active material (e.g., S/t-CNTs-8 h, about $0.5 \mathrm{~g}$ ), $10 \mathrm{wt} \%$ conductive carbon (superP-Li, Timcal), 3 wt $\%$ carboxymethyl cellulose sodium (CMC) and $3 \mathrm{wt} \%$ styrene butadiene rubber (SBR). The mixed slurry was pasted on a copper foil and cut into small discs. The electrolyte was $1.3 \mathrm{M} \mathrm{LiPF}_{6}$ in ethylene carbonate (EC) and diethyl carbonate (DEC) with the volume ratio of EC/DEC = $3: 1$. The cells were assembled in a glove box filled with pure argon in the presence of an oxygen scavenger and a sodiumdrying agent and then aged for $12 \mathrm{~h}$ at room temperature before the electrochemical test between $0.01 \mathrm{~V}$ and $2.5 \mathrm{~V}(v s$. Li/ $\mathrm{Li}^{+}$). Cyclic voltammetry (CV) and electrochemical impedance spectra (EIS) measurements were recorded by the electrochemical workstation system IM6ex (Zahner).

\section{Results and discussion}

Fig. 1 shows the X-ray diffraction (XRD) patterns of the selected samples S/t-CNTs-24 h, S/t-CNTs- $48 \mathrm{~h}, \mathrm{~S} / \mathrm{t}-\mathrm{CNTs}-64 \mathrm{~h}, \mathrm{~S} / \mathrm{t}-\mathrm{CNTs}-$ $100 \mathrm{~h}, \mathrm{CNTs}$ and treated-CNTs. The (002) diffraction peak of graphite can be obviously observed from the XRD patterns of the CNTs and treated-CNTs. The diffraction peaks at $2 \theta=26.7^{\circ}$,

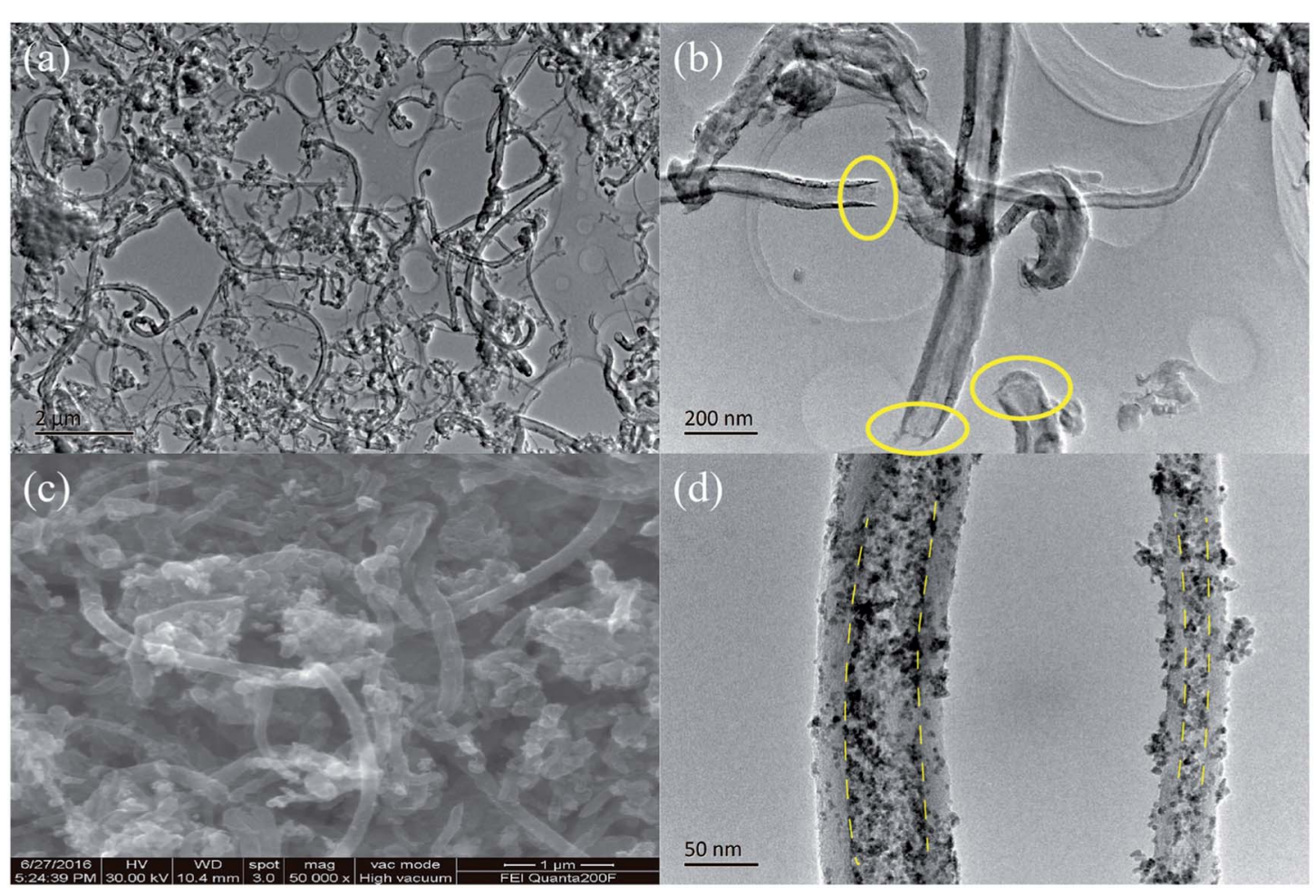

Fig. 2 TEM images of treated-CNTs (a) and (b), SEM image (c) and TEM image (d) of the final product S/t-CNTs-100 h composite. 


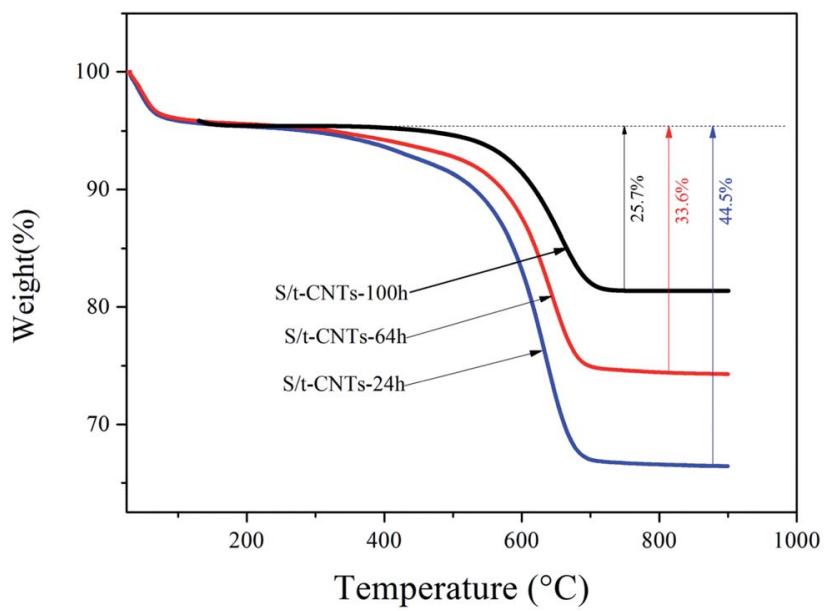

Fig. 3 TG curves of the final products S/t-CNTs-24 h, $-64 \mathrm{~h}$ and $-100 \mathrm{~h}$.

$34.1^{\circ}, 51.5^{\circ}, 65.5^{\circ}$ can be assigned to $110,101,211$ and 112 planes of the cassiterite $\mathrm{SnO}_{2}$, respectively. No impurities such as $\mathrm{SnCl}_{2}$ and $\mathrm{SnO}$ were found. The highly broad diffraction peaks indicate the nanocrystalline nature of the composites, which will contribute to the high rate electrochemical performance of the composites. The mean particle size of the $\mathrm{SnO}_{2}$ particles estimated from Scherer's formula is about $4-5 \mathrm{~nm}$ agreeing with the TEM results in the follow discussion.

After the oxidation by the hydrogen peroxide and nitric acid solution, the 1D tubular structure of CNTs is retained. The long CNTs are cut down to short tubes and most tips are opened, seen in Fig. 2(a) and (b). Fig. 2(c) and (d) show the SEM and TEM images of the final product S/t-CNTs-100 h. Both SEM and TEM images confirm that the outer surfaces of CNTs are covered with few $\mathrm{SnO}_{2}$ particles. But most of $\mathrm{SnO}_{2}$ particles were filled in the hollow cavity of CNTs indicated by the clear boundary, seen in Fig. 2(d). Otherwise, from the image Fig. 2(d), it can be seen that the size distribution of the $\mathrm{SnO}_{2}$ particles is very uniform, and the average diameter is about $4 \sim 5 \mathrm{~nm}$ which is consistent with the result calculated from the XRD data.

The actual content of $\mathrm{SnO}_{2}$ in $\mathrm{SnO}_{2}$ /CNTs composites was analyzed by TG method, the result is showed in Fig. 3. All samples were heated from room temperature to $1000{ }^{\circ} \mathrm{C}$ in air atmosphere. From the Fig. 3, it can be seen that the main mass loss occurred in the range of $200-800{ }^{\circ} \mathrm{C}$, which is caused by the combustion of CNTs in the composite..$^{28,30} \mathrm{So}$, the content of $\mathrm{SnO}_{2}$ in the $\mathrm{SnO}_{2} / \mathrm{CNTs}$ composite is about $74.3 \mathrm{wt} \%, 66.4 \mathrm{wt} \%$ and $55.3 \mathrm{wt} \%$ respectively when the reaction time is $100 \mathrm{~h}, 64 \mathrm{~h}$ and $24 \mathrm{~h}$. These data suggest that the content of $\mathrm{SnO}_{2}$ filled in the cavity of CNTs will increase with the increase of reaction time, which will result in the increase of charge \& discharge capacity of the composite.

For comparison, the selected charge \& discharge profiles of S/t-CNTs-100 h composite, $\mathrm{SnO}_{2}$-CNTs $\left(\mathrm{SnO}_{2}\right.$ particles and CNTs were mixed simply by grinding) and bare $\mathrm{SnO}_{2}$ particles at a current density of $0.4 \mathrm{~A} \mathrm{~g}^{-1}$ between the potential range of 0.01-2.5 $\mathrm{V}$ (vs. $\left.\mathrm{Li} / \mathrm{Li}^{+}\right)$are shown in Fig. 4(a). The discharge capacity was calculated based on the mass of active materials ( $\mathrm{S}$ / t-CNTs-100 h composite, $\mathrm{SnO}_{2}$-CNTs or $\mathrm{SnO}_{2}$ ). The initial discharge capacity of the S/t-CNTs-100 h composite is greater than $2200 \mathrm{~mA} \mathrm{~h} \mathrm{~g}^{-1}$, and it decrease to $1105 \mathrm{~mA} \mathrm{~h} \mathrm{~g}^{-1}$ in the next cycle. The reasons of the serious irreversible capacity loss are mainly attributed to the reduction of $\mathrm{SnO}_{2}$ by $\mathrm{Li}$ metal, ${ }^{32}$ the formation of SEI films and the side reactions between electrolyte and the functional groups on the surface of CNTs. The case of sample $\mathrm{SnO}_{2}$-CNTs and bare $\mathrm{SnO}_{2}$ are the same as for $\mathrm{S} / \mathrm{t}$ CNTs-100 h, but their initial discharge capacity are much lower than that of $\mathrm{S} / \mathrm{t}-\mathrm{CNTs}-100 \mathrm{~h}$ composite and decrease very quickly. After 20 cycles, the S/t-CNTs-100 h composite can still deliver a high discharge capacity of $829 \mathrm{~mA} \mathrm{~h} \mathrm{~g}^{-1}$, while sample $\mathrm{SnO}_{2}$-CNTs and $\mathrm{SnO}_{2}$ can only release a much lower discharge capacity of $585 \mathrm{~mA} \mathrm{~h} \mathrm{~g}^{-1}$ and $313 \mathrm{~mA} \mathrm{~h} \mathrm{~g}^{-1}$.

Fig. 4(b) shows the cycling performance of S/t-CNTs-100 h, $-72 \mathrm{~h},-64 \mathrm{~h},-48 \mathrm{~h},-24 \mathrm{~h},-16 \mathrm{~h},-8 \mathrm{~h}$ composites, $\mathrm{SnO}_{2}$-CNTs, $\mathrm{SnO}_{2}$ particles and treated-CNTs working at a current density of $0.4 \mathrm{~A} \mathrm{~g}^{-1}$ between $0.01-2.5 \mathrm{~V}$. All the S/t-CNTs composites show an excellent cycling performance and the discharge capacity increase gradually with the increase of the reaction time means the content of $\mathrm{SnO}_{2}$ in the composite increased with the increase of the reaction time, which is agreement with the result of TG characterization. Sample S/t-CNTs-100 h can deliver high discharge capacity of $743 \mathrm{~mA} \mathrm{~h} \mathrm{~g}{ }^{-1}$ after 100 cycles. The bare
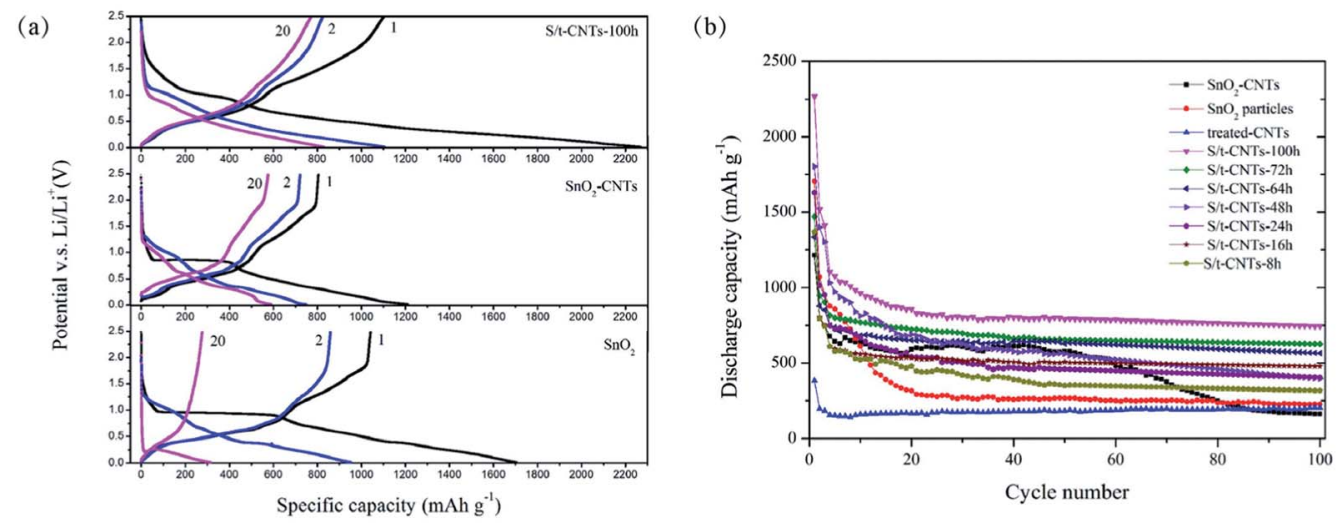

Fig. 4 The selected charge 8 discharge curves (a) and cycle performance (b) of S/t-CNTs composites, $\mathrm{SnO}_{2}-\mathrm{CNTs}$ and $\mathrm{SnO} 2$ working at current density of $0.4 \mathrm{~A} \mathrm{~g}^{-1}$. 
$\mathrm{SnO}_{2}$ particles can only deliver a discharge capacity of $225 \mathrm{~mA} \mathrm{~h} \mathrm{~g}{ }^{-1}$ after 100 cycles, just a little higher than that of treated-CNTs. It is worth noting that sample $\mathrm{SnO}_{2}$-CNTs can release a high discharge capacity of $617 \mathrm{~mA} \mathrm{~h} \mathrm{~g}^{-1}$ in the first few cycles, which is higher than that of sample S/t-CNTs-48 h, $-24 \mathrm{~h}$, $-16 \mathrm{~h}$ and $-8 \mathrm{~h}$. However, after 50 cycles its discharge capacity begin to decay sharply and only remain $162 \mathrm{~mA} \mathrm{~h} \mathrm{~g}^{-1}$ at the $100^{\text {th }}$ cycle. This should be caused by the huge and iterative volume change in the process of charge \& discharge which will result in the failure of the electrode. Therefore, $\mathrm{SnO}_{2}$ particles mixing with CNTs by simply grinding cannot improve its electrochemical properties for long cycle.

The improved lithium storage performance of $\mathrm{S} / \mathrm{t}-\mathrm{CNTs}$ composites can be explained by the effect of small size of $\mathrm{SnO}_{2}$ and the restriction of CNTs. ${ }^{33,34}$ Ultra-small $\mathrm{SnO}_{2}$ particles can make the diffusion pathway of the Li-ions shorten ${ }^{35,36}$ and also make electrolyte diffuse better. On the other hand, the aggregation and large volume change of $\mathrm{SnO}_{2}$ during the process of charge \& discharge is restricted by the unique tubular structure of CNTs. ${ }^{37,38}$

The electrochemical performance of S/t-CNTs-100 h composite and $\mathrm{SnO}_{2}$-CNTs at different current density is given in Fig. 5. The reversible discharge capacities of S/t-CNTs-100 $\mathrm{h}$ are $962 \mathrm{~mA} \mathrm{~h} \mathrm{~g}^{-1}$, $837 \mathrm{~mA} \mathrm{~h} \mathrm{~g}^{-1}, 680 \mathrm{~mA} \mathrm{~h} \mathrm{~g}^{-1}, 625 \mathrm{~mA} \mathrm{~h} \mathrm{~g}^{-1}$ and $566 \mathrm{~mA} \mathrm{~h} \mathrm{~g}^{-1}$ after successively working at a current density of $0.4 \mathrm{~A} \mathrm{~g}^{-1}, 0.8 \mathrm{~A} \mathrm{~g}^{-1}$, $1.6 \mathrm{~A} \mathrm{~g}^{-1}, 3 \mathrm{~A} \mathrm{~g}^{-1}$ and $4 \mathrm{~A} \mathrm{~g}^{-1}$ for 10 cycles, respectively. While, the $\mathrm{SnO}_{2}$-CNTs delivers discharge capacity of $676 \mathrm{~mA} \mathrm{~h} \mathrm{~g} \mathrm{~g}^{-1}$, $588 \mathrm{~mA} \mathrm{~h} \mathrm{~g}^{-1}, 484 \mathrm{~mA} \mathrm{~h} \mathrm{~g}^{-1}, 253 \mathrm{~mA} \mathrm{~h} \mathrm{~g}^{-1}$ and $56 \mathrm{~mA} \mathrm{~h} \mathrm{~g}^{-1}$ when cycled at $0.4 \mathrm{Ag}^{-1}, 0.8 \mathrm{~A} \mathrm{~g}^{-1}, 1.6 \mathrm{Ag}^{-1}, 3 \mathrm{Ag}^{-1}$ and $4 \mathrm{~A} \mathrm{~g}^{-1}$ for 10 cycles, respectively. The rate performance of S/t-CNTs-100 h composite is much better than that of $\mathrm{SnO}_{2}$-CNTs. Even when the current density increased to $8 \mathrm{~A} \mathrm{~g}^{-1}$, the composite can still deliver a discharge capacity of $458 \mathrm{~mA} \mathrm{~h} \mathrm{~g}{ }^{-1}$. And when the current density decreased to $0.4 \mathrm{~A} \mathrm{~g}^{-1}$, a greatly high discharge capacity of $998 \mathrm{~mA} \mathrm{~h} \mathrm{~g}{ }^{-1}$ can be retained, revealing the nature of good conductivity of the composite. The curve of 500 cycles of S/t-CNTs$100 \mathrm{~h}$ composite working at a current density of $4 \mathrm{~A} \mathrm{~g}^{-1}$ is illustrated in the Fig. 5 too. It can be seen the discharge capacity of the

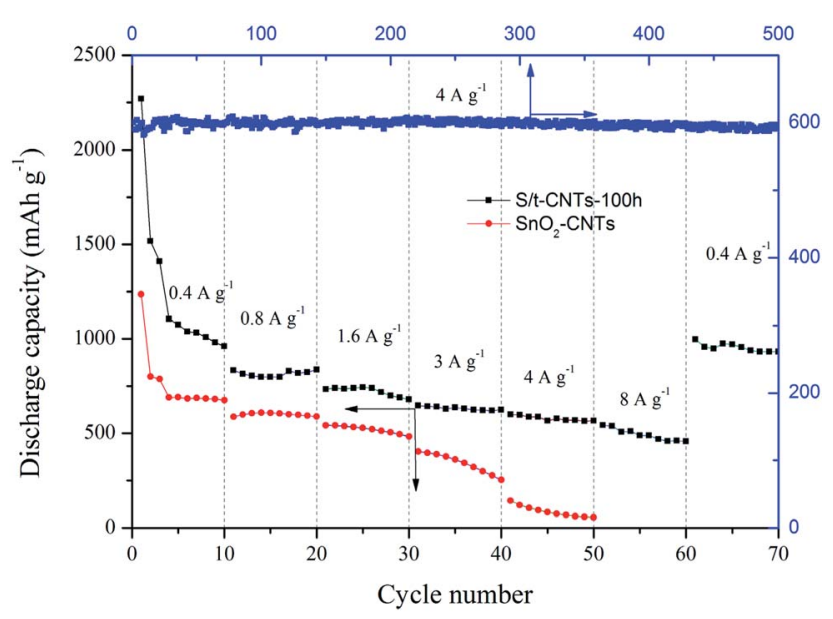

Fig. 5 Rate capability of the S/t-CNTs-100 h composite and $\mathrm{SnO}_{2}-$ CNTs; and cycle performance at current density of $4 \mathrm{~A} \mathrm{~g}^{-1}$ of sample S/ $\mathrm{t}$-CNTs-100 h.

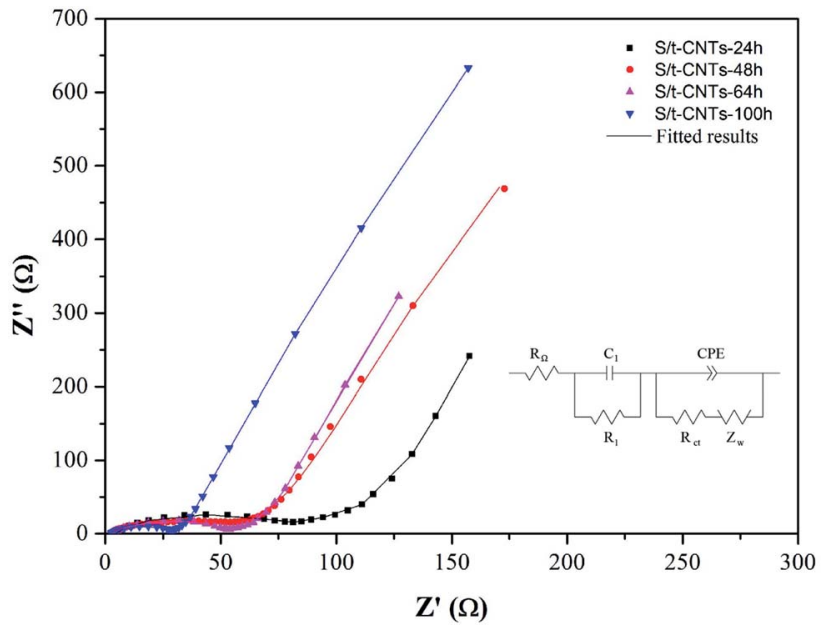

Fig. 6 EIS curves of sample S/t-CNTs-24 h, -48 h, $-64 \mathrm{~h}$ and $-100 \mathrm{~h}$ composite.

Table 1 Equivalent circuit parameters of the sample S/t-CNTs-24 h, $-48 \mathrm{~h},-64 \mathrm{~h}$ and $-100 \mathrm{~h}$

\begin{tabular}{llll}
\hline Samples & $R_{\Omega} / \Omega \mathrm{cm}^{2}$ & $R_{1} / \Omega \mathrm{cm}^{2}$ & $R_{\mathrm{ct}} / \Omega \mathrm{cm}^{2}$ \\
\hline S/t-CNTs-24 h & 5.51 & 78.72 & 43.41 \\
S/t-CNTs-48 h & 2.54 & 54.20 & 55.45 \\
S/t-CNTs-64 h & 3.75 & 52.01 & 29.37 \\
S/t-CNTs-100 h & 2.88 & 29.61 & 24.05
\end{tabular}

composite is almost no attenuation, which means the excellent cycling stabilization of the composite in the long cycle. It is believed that the excellent performance at different current density and the long life are mainly benefit from the special core-tubule structure of the S/t-CNTs composite. CNTs can limit the huge and reiterative volume change of $\mathrm{SnO}_{2}$ and provide a good conductive network for the anode in the same time during the process of charge \& discharge. ${ }^{39,40}$

Further investigation of the effect of reaction time on the electron transfer resistance of the $\mathrm{S} / \mathrm{t}$-CNTs composites by the EIS method is illustrated in Fig. 6. The equivalent circuit is shown in Fig. 6 too, where $R_{\Omega}, R_{\mathrm{l}}, R_{\mathrm{ct}}, Z_{\mathrm{w}}$ and CPE are corresponded to the electrolyte resistance, SEI resistance, chargetransfer resistance, ${ }^{29,41}$ Warburg impedance associated with the diffusion of $\mathrm{Li}^{+}$and constant phase element related to double layer capacitance, respectively. ${ }^{35,36,42}$ The fitting results are listed in Table 1. As can be seen, with the increase of reaction time, $R_{\mathrm{l}}$ and $R_{\mathrm{ct}}$ are both decrease. That is, a longer reaction time will make more $\mathrm{SnO}_{2}$ nanoparticles enter into the cavity of CNTs. And the contact between the $\mathrm{SnO}_{2}$ nanoparticles or $\mathrm{SnO}_{2}$ nanoparticles and CNTs become more closely result in the decrease of resistance and the high electrochemical performance of the S/t-CNTs composites.

\section{Conclusion}

A series of S/t-CNTs composites with different reaction times were prepared by a facile method. The results indicated that the 
amount of $\mathrm{SnO}_{2}$ nanoparticles filled in the hollow cavity of the CNTs will increase with the increase of reaction time. At the same time, the electrochemical performance of S/t-CNTs composites would become better because of the special coretubule structure. The composite with reaction time $100 \mathrm{~h}$ released an ultra-high discharge capacity of $2200 \mathrm{~mA} \mathrm{~h} \mathrm{~g}^{-1}$ in the first cycle and maintained at about $829 \mathrm{~mA} \mathrm{~h} \mathrm{~g}^{-1}$ after about 20 cycles at a current density of $0.4 \mathrm{~A} \mathrm{~g}^{-1}$. Even when the current density increased to $8 \mathrm{~A} \mathrm{~g}^{-1}$, the composite can still deliver a steady capacity of $458 \mathrm{~mA} \mathrm{~h} \mathrm{g^{-1 }}$ and has a long cycle life.

\section{Conflicts of interest}

There are no conflicts to declare.

\section{Acknowledgements}

This work was supported by National Natural Science Foundation of China (Grant No. 51662029, 21263016 and 21365013).

\section{References}

1 D. Ahn, X. Xiao, Y. Li, A. K. Sachdev, H. W. Park, A. Yu and Z. Chen, J. Power Sources, 2012, 212, 66.

2 V. Aravindan, J. Sundaramurthy, E. N. Kumar, P. S. Kumar, W. C. Ling, R. von Hagen, S. Mathur, S. Ramakrishna and S. Madhavi, Electrochim. Acta, 2014, 121, 109.

3 M. V. Kharlamova, Prog. Mater. Sci., 2016, 77, 125.

4 S. Chen, Y. Xin, Y. Zhou, F. Zhang, Y. Ma, H. Zhou and L. Qi, J. Mater. Chem. A, 2014, 2, 15582.

5 S. Reddy, R. Du, L. Kang, N. Mao and J. Zhang, Appl. Catal., B, 2016, 194, 16.

6 X. Dai, K. Du, Z. Li, H. Sun, Y. Yang, W. Zhang and X. Zhang, Int. J. Hydrogen Energy, 2015, 40, 8877.

7 W. Yu, L. Zhang, P. Hou, F. Li, C. Liu and H. Cheng, Adv. Energy Mater., 2016, 6, 1501755.

8 Y. J. Hong and Y. C. Kang, Carbon, 2015, 88, 262.

9 V. M. Krishna and T. Somanathan, Biomater. Sci., 2016, 39, 1079.

10 J. Li, X. Wang, H. Duan, Y. Wang and C. Luo, Mater. Sci. Eng., C, 2016, 64, 391.

11 H. Yang, G. Sun, L. Zhang, Y. Zhang, X. Song, J. Yu and S. Ge, Sens. Actuators, B, 2016, 234, 658.

12 Y. I. Idota, T. Kubota, A. Matsufuji, Y. Maekawa and T. Miyasaka, Science, 1997, 276, 1395.

13 J. Liang, X. Yu, H. Zhou, H. B. Wu, S. Ding and X. W. D. Lou, Angew. Chem., Int. Ed., 2014, 53, 12803.

14 X. Zhou, L. Wan and Y. Guo, Adv. Mater., 2013, 25, 2152.

15 M. Park, G. Wang, Y. Kang, D. Wexler, S. Dou and H. Liu, Angew. Chem., Int. Ed., 2007, 46, 750.
16 Y. Wang, H. C. Zeng and J. Y. Lee, Adv. Mater., 2006, 18, 645. 17 Y. J. Hong, M. Y. Son and Y. C. Kang, Adv. Mater., 2013, 25, 2279.

18 Z. Wang, D. Luan, F. Y. C. Boey and X. W. D. Lou, J. Am. Chem. Soc., 2011, 133, 4738.

19 C. Wang, Y. Zhou, M. Ge, X. Xu, Z. Zhang and J. Z. Jiang, J. Am. Chem. Soc., 2010, 132, 46.

20 X. W. Lou, C. M. Li and L. A. Archer, Adv. Mater., 2009, 21, 2536.

21 H. Cong, S. Xin and S. Yu, Nano Energy, 2015, 13, 482.

22 S. H. Choi, J. Lee and Y. C. Kang, ACS Nano, 2015, 9, 10173.

23 Y. Cheng, J. Huang, J. Li, Z. Xu, L. Cao and H. Qi, J. Power Sources, 2016, 324, 447.

24 Q. Liu, Y. Dou, B. Ruan, Z. Sun, S. Chou and S. X. Dou, Chem.-Eur. J., 2016, 22, 5853.

25 S. P. Kim, M. Y. Choi and H. C. Choi, Appl. Surf. Sci., 2015, 357, 302.

26 R. Oulton, J. P. Haase, S. Kaalberg, C. T. Redmond, M. J. Nalbandian and D. M. Cwiertny, Environ. Sci. Technol., 2015, 49, 3687.

27 W. Yu, P. Hou, L. Zhang, F. Li, C. Liu and H. Cheng, Chem. Commun., 2010, 46, 8576.

$28 \mathrm{~J} . \mathrm{Yu}$ and Y. Xia, Electrochim. Acta, 2014, 147, 720.

29 Z. Zhang, L. Wang, J. Xiao, F. Xiao and S. Wang, ACS Appl. Mater. Inter., 2015, 7, 17963.

30 C. Xu and J. Chen, Ceram. Int., 2016, 42, 14287.

$31 \mathrm{H}$. Zhang, H. Song, X. Chen, J. Zhou and H. Zhang, Electrochim. Acta, 2012, 59, 160.

$32 \mathrm{~J} . \mathrm{Xu}, \mathrm{S} . \mathrm{Gu}$ and B. Lu, RSC Adv., 2015, 5, 72046.

33 T. Ma, S. Wen, L. Yan, C. Wu, C. Zhang, M. Zhang and Z. Su, Phys. Chem. Chem. Phys., 2016, 18, 23643.

34 C. Ma, W. Zhang, Y. He, Q. Gong, H. Che and Z. Ma, Nanoscale, 2016, 8, 4121.

35 M. Steimecke, S. Ruemmler and M. Bron, Electrochim. Acta, 2015, 163, 1.

36 Q. Guo, Z. Sun, M. Gao, Z. Tan, B. Zhang and D. S. Su, J. Energy Chem., 2013, 22, 347.

37 Z. Jiang, D. Zhang, Y. Li, H. Cheng, M. Wang, X. Wang, Y. Bai, H. Lv, Y. Yao, L. Shao and Y. Huang, Appl. Surf. Sci., 2014, 317, 486.

38 J. Wang, J. Xi, L. Zhang, J. Zhang, X. Guo, J. Zhao, C. Song and L. Wang, Electrochim. Acta, 2013, 112, 480.

39 Y. Qu, H. Wang, H. Chen, M. Han and Z. Lin, Sens. Actuators, $B, 2016,228,595$.

40 J. Lin, M. Chou and Y. Kuo, J. Alloys Compd., 2014, 589, 472. 41 Q. Tian, Y. Tian, Z. Zhang, L. Yang and S. Hirano, J. Power Sources, 2015, 291, 173.

42 H. Liu, J. Mater. Sci.: Mater. Electron., 2014, 25, 3353. 